biodiversity hotspots, suggesting that current conservation planning does not adequately cover these evolutionary rarities. Curr. Biol. http://doi.org/r9f (2014)

\section{CIVIL ENGINEERING}

\section{Seismic 'shield' stops quake shake}

An array of deep holes in the ground seems to lessen shaking in certain locations during a simulated earthquake.

Stéphane Brûlé of soilengineering company Ménard in Nozay, France, and his colleagues drilled a grid of boreholes 5 metres deep into the soil near Grenoble. A crane then lowered a probe into the ground nearby, where it vibrated to simulate an earthquake. The boreholes were located in places where the seismic waves interfered with one another and cancelled each other out. Thus, the array of holes deflected much of the seismic energy and bounced it back towards the source.

The approach could lead to new ways to protect buildings from shaking during earthquakes, the authors say. Phys. Rev. Lett. 112, 133901 (2014)

\section{NEUROBIOLOGY}

\section{Surprising effects of prion drug}

\section{A chemical that combats} pathogenic prion proteins in infected mouse cells worsens the problem in cells from other species. The finding could explain why the drug, quinacrine, has been ineffective in many clinical trials.

Prion infections turn healthy proteins into abnormally folded forms, which cause fatal neurodegenerative diseases in humans and other animals. Quinacrine reduces this misfolding in mouse cells, but Glenn Telling and his colleagues at Colorado

State University in Fort

Collins discovered that the drug has the opposite effect in deer, elk and moose cells, causing the proteins to misfold even more. The researchers think that small differences in prion protein sequences between species could be to blame.

Drug developers will need to rethink how they screen molecules for antiprion activity, the authors say.

Proc. Natl Acad. Sci. USA http://doi.org/r9d (2014)

\section{MATERIALS \\ Printer squirts out nanotubes}

Inkjet printers can produce thin films of carbon nanotubes for use as electrodes in stretchy electronic circuits.

Yongtaek Hong and his colleagues at Seoul National University printed layers of single-walled carbon nanotubes onto a stretchable silicon-based material. The authors found that the electrical properties of the films improved after washing them with water and soaking them in diluted nitric acid. Furthermore, a film with five layers of nanotubes performed better than a single layer, maintaining conductive properties under $100 \%$ tensile strain.

This method is simpler and more scalable than previous ones, the authors say.

Appl. Phys. Lett. 104, 113103 (2014)

\section{NEUROSCIENCE}

\section{Turn on the light to make myelin}

Brain circuits change throughout life, and researchers in California have discovered a mechanism for one such change: the thickening of the myelin sheath that surrounds nerve fibres and helps neurons to fire.

Michelle Monje and her co-workers at Stanford

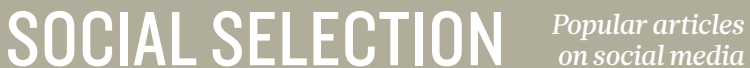

\title{
Lionfish prove a main draw on Twitter
}

Lionfish took a bite of Twitter attention at the start of this month in a paper that reveals some unintended effects of population-control measures that could undermine future efforts.

Isabelle Côté at Simon Fraser University in Burnaby, Canada, and her team, looked at what happens after invasive predatory lionfish (Pterois volitans/miles) were culled at coral-reef sites in the Bahamas. The effects on surviving fish were marked: they became less active and hid deeper in the reefs during the day compared with fish in reefs where no culls took place. The wary lionfish also seemed able to spot approaching divers from a greater distance.

As Côté pointed out on Twitter, these changes in behaviour could lead to underestimating the size of the lionfish population.

PLoS ONE 9, e94248 (2014)

\begin{tabular}{l|l} 
Based on data from altmetric.com. & DNATURE.COM \\
$\begin{array}{l}\text { Altmetric is supported by Macmillan } \\
\text { Science and Education, which owns }\end{array}$ & $\begin{array}{l}\text { For more on } \\
\text { Nature Publishing Group. }\end{array}$ \\
\hline
\end{tabular}

University School of Medicine studied mice that had been engineered so that light can stimulate neurons in the brain's premotor cortex. This stimulation resulted in the generation of more cells called oligodendrocytes, which make myelin, and a thickening of the myelin sheath in this and other brain regions. Furthermore, mice that were stimulated with light and had thicker myelin showed better motor function than normal animals.

The results could point to ways of boosting myelin formation in neurodegenerative diseases such as multiple sclerosis, the authors say.

Science http://doi.org/r9g (2014)

Fast moves of
fleeing fruit flies

To dodge predators, flies in flight execute banked turns in just a few wingbeats much faster than the steering motions that have been previously observed in flies. Michael Dickinson and his colleagues at the University of Washington in Seattle used three high-speed cameras operating at 7,500 frames per second to capture the flight responses of a fruit fly species (Drosophila hydei; pictured) when it evades a threat looming in front of it. They found that with slight changes in wing motion, the insects use a combination of side-to-side rotation of the body and front-to-back body tilting to rapidly steer away from threats.

The flies then quickly rotate back to a normal position as they accelerate away from danger.

Science 344, 172-177 (2014)
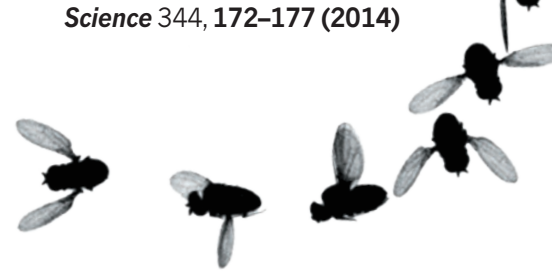

$\rightarrow$ NATURE.COM

For the latest research published by Naturevisit:

www.nature,com/latestresearch 